\title{
Effects of Crude Oil Contaminant on the Engineering Properties of Concrete
}

\author{
George Abednego, Onungwe Ishmael, Oba Achemie, Akpan Paul, Sarogoro Samuel
}

Department of Civil Engineering, Rivers State Polytechnic, Bori-Ogoni, Rivers State, Nigeria, West Africa

Email address:

tonsoky@yahoo.com (G. Abednego), ishmael.onungwe@gmail.com (I. Onungwe), achemie25@gmail.com (O. Achemie), paulynciap06@yahoo.com (A. Paul),ndesarosr@yahoo.com (S. Samuel)

\section{To cite this article:}

George Abednego, Onungwe Ishmael, Oba Achemie, Akpan Paul, Sarogoro Samuel. Effects of Crude Oil Contaminant on the Engineering Properties of Concrete. American Journal of Civil Engineering. Vol. 3, No. 5, 2015, pp. 178-182. doi: 10.11648/j.ajce.20150305.16

\begin{abstract}
The artificial application of crude oil in various percentages in concrete mix constituent to under study the service interaction of concrete in contact with oil was carried out. The research contained herein present the investigation, analysis and comparative results obtained from a total of 96 concrete cubes sample consisting of 12 control cubes, $120 \%$ contaminated cubes cured in Bodo crude oil water and 72various percentages of crude oil contaminated cubes cured in potable water. The tests conducted were slump and flow rate in terms of freshly mixed concrete and compressive strength in terms of hardened content. The OPC concrete mix which adopted 0.5 water cement ratio was cured for 7, 14, 21 and 28 days in its cubes form and the results obtained indicated that concrete is highly susceptible when in contact with crude oil. Its contact with crude oil causes it to deterioration as well as slow strength development and increased percentage flow rate. The difference between the control mix and the $25 \%$ crude oil contamination was $16 \mathrm{~N} / \mathrm{mm}^{2}$ at 28 days, which explicitly spells out the consequences of crude oil effect on the properties of concrete structures.
\end{abstract}

Keywords: Crude Oil, Contaminated Water, Compressive Strength, Slump, Concrete Flow Rate

\section{Introduction}

The amount of crude oil contamination of soil and the environment has continually increased and presently, it constitutes a significant fraction of waste material in the environment [1]. Contaminants in aggregates or concrete constituents does not only affect the appearance of concrete in terms of color and rotting but also the strength, durability, abrasion, water tightness, volume stability, freeze and thaw resistance and resistance to deicing chemicals. The effect of crude oil on some engineering properties of concrete in a crude oil contaminated area had been considered by some authors and one of such authors [2], on a general note observed that there was high reduction in the compressive strength and about $11 \%$ reduction in splitting-tensile strength of concrete when soaked in crude oil. Concrete deterioration and cracking in marine environment is more severe than in any other terrestrial environment, hence it has been observed that deterioration occur as a result of such factors as physical and chemical characteristics of repair compound, initial curing periods, environmental conditions, among other factors [3], in his work on some properties of crude oil, soaked concrete exposed at ambient temperature observed variations in mechanical properties with time. Furthermore, he reiterated that the variation in compressive strength length change and absorption characteristics of typical offshore concrete structures exposed to crude oil for 365 days compromised the durability and serviceability of such structure. However, studies by [4] showed that factors significantly affecting concrete properties include conditions of curing prior to exposure, moisture condition of concrete at the time of exposure, storage temperature of crude oil as well as the type of cement. The occurrence of concrete deterioration and cracking as a result of crude oil spill, has remained a green area in literature. Observation showed that for four decades, Nigeria has continued to experience remarkable increase in operational activities in her oil and gas exploration, exploitation, refining and product marketing which is concentrated in the Niger Delta region and that the region has been mired by various degrees of health and environmental pollution problems. Regular crude oil spillage on surface and subsurface water sources, erosion and drainage problems of the built environs culminating to incessant failure of buildings and other onshore structures have become a regular news item 
[5]. [6] inferred that the optimum crude oil contamination for the achievement of normal compressive strength is as low as $0.3 \%$. The research of [7] on the effect of crude oil contamination on the index properties, strength and permeability of lateritic clay showed that the liquid limit, plastic limit and plasticity index of the soil increased as its crude oil content increased. The specific gravity, optimum moisture content, maximum dry unit weight, CBR and permeability of the soil decreased as its crude oil content increased. Crude oil contaminated soil requires stabilization or remediation before using it as a construction material. The studies of [8] also showed that A 18-90\% compressive strength was lost due to $2.5-25 \%$ crude oil contamination, respectively. These and other physical observatory factors has informed the research contained herein which focuses on artificially contaminating concrete sample constituent in terms of fine aggregate in various percentages and crude oil contaminated water sample and subjecting these samples when constituted as concrete to investigation on the effect of the contaminations on the properties of the concrete both in fresh and hardened state which actually models the situation in Bodo due to oil facility failure, crude oil spillage or vandalism as most constructional materials or concrete constituents are extracted from contaminated river bodies or most contaminated water are used for construction.

\section{Materials and Method}

\subsection{Materials}

The cement used for this study is one of the available commercial brands of Ordinary Portland Cement (OPC), however care was taken in the cement material purchase as well as the conducting of the practical to ensure test reliability. Aggregates used were coarse aggregate of $12 \mathrm{~mm}$ maximum size conforming to [9] which was obtained from Akamkpa quarry in Cross River State, while the fine aggregate was natural white color river bed sand obtained in Bori Rivers State. The fine aggregate was oven dried having determined the moisture content to achieve dry surface condition in order to ensure the actualization of materials void of saturation so as not to affect the water cement ratio, thereby bringing the aggregate to conform to [10] specification. Other tests and procedure carried out in this research work include grain size analysis, slump test, flow table test, cubes casting, curing and compressive strength test using a digital crushing machine at Rivigo JV Nigeria Limited, Ogoni-Andoni-Opobo Road project site base. The sieve analysis was carried out in accordance with [11] in order to determine particle grading curve of the aggregates from where it was deduced that fine aggregate fell in zone 2 consisting of fine, medium and coarse sand with coefficient of uniformity $(\mathrm{Cu})$ of 1.69 and coefficient of curvature $(\mathrm{Cc}) 0.84$ indicating a well graded fine aggregate. The coarse aggregate fell into zone 3 consisting of fine and medium gravel with $(\mathrm{Cu})$ of 1.96 and $(\mathrm{Cc})$ of 1.01 indicating a well graded coarse aggregate. The crude oil used was obtained from one of the oil fields within the locality.

\subsection{Methods}

Concrete mix design of 1:2:4 at water cement ratio of 0.5 was adopted and batched in weight in accordance with British Standards. The mixed design covers three sets of sample including samples of $0 \%$ contaminated cubes cured in portable water which serves as control, $0 \%$ contaminated cubes cured in Bodo crude oil contaminated water and different levels of artificial contaminated cubes of $(2.5 \%, 5 \%, 10 \%, 15 \%, 20 \%$ and $25 \%$ ) cured in fresh water. These three samples were compared in terms of freshly mixed concrete and compressive strength in terms of hardened concrete. The concrete constituents were thoroughly mixed in a clean dry manual tilting concrete mixing drum with a total of 96 cubes produced. The material mix proportion is as shown in table 2 .

\section{Tests on Fresh Concrete Sample}

Basically the tests conducted on the freshly mixed concrete sample were slump and flow table test. Results obtained from these tests are as shown in table 3 and 4 respectively. The slump test was carried out on both the control and contaminated samples to check workability in accordance with the procedural steps as given in [9]. The flow table test was conducted to observe the concrete sample consistency and cohesiveness as well as the degree of segregation. The flow table test was carried out in accordance with the procedure outlined in [12]. The hardened concrete cube test conducted on the sample was the compressive strength test using a digital crushing machine at Rivigo JV Nigeria Limited. The cubes tested for totaling 96 cubes comprising of $120 \%$ contaminated cubes as control and 84 contaminated cubes of $150 \mathrm{mmx} 150 \mathrm{mmx} 150 \mathrm{~mm}$. The cubes were all removed from its mould within 24 hours of its cast and cured in a water curing tank within a room temperature and later removed from the curing tank according to the duration of crushing and was tested for compressive strength in accordance with [13]. The results obtained are as shown in table 5 .

\section{Results}

Table 1. Properties of Nigerian Crude oil.

\begin{tabular}{llll}
\hline S/No & Parameters & Rate/Unit & Magnitude \\
\hline 1 & Gravity Degree & API & $<35.00$ \\
2 & Specific Gravity & $15^{\circ} \mathrm{C}$ & 0.812 \\
3 & Sulphur Content & $\%$ by weight & 0.30 \\
4 & Moisture Content & $\%$ by volume & 0.40 \\
5 & Wax Content & $\%$ by weight & 7.0 \\
6 & Carbon Residue & $\%$ by weight & 2.10 \\
7 & Melting point & ${ }^{\circ} \mathrm{C}$ & 57 \\
8 & Viscosity & $21^{\circ} \mathrm{C}$ & 6.81 \\
9 & Acidity & $\mathrm{Mg} / \mathrm{KOH} / \mathrm{g}$ & 0.05 \\
\hline
\end{tabular}

*Source: [14]. 
Table 2. Materials Mix Proportion.

\begin{tabular}{lllllll}
\hline S/No & Cement $\mathbf{( K g )}$ & Water $\mathbf{( K g )}$ & Fine $\mathbf{( K g )}$ & Coarse $\mathbf{K g})$ & Crude oil * $(\mathbf{K g})$ & \% Contamination \\
\hline 1 & 135 & 67.5 & 270 & 540 & 0 & 0 \\
2 & 135 & 67.5 & 270 & 540 & 6.75 & 2.5 \\
3 & 135 & 67.5 & 270 & 540 & 27 & 10 \\
4 & 135 & 67.5 & 270 & 540 & 40.5 & 15 \\
5 & 135 & 67.5 & 270 & 540 & 54 & 20 \\
6 & 135 & 67.5 & 270 & 540 & 67.5 & 25 \\
\hline
\end{tabular}

* The crude oil contamination value was obtained with respect to fine aggregate.

Table 3. Slump Test Result.

\begin{tabular}{llll}
\hline S/No & \% Contamination & Slump $(\mathbf{m m})$ & Workability \\
\hline 1 & 0 & 20 & Very Low \\
2 & 2.5 & 45 & Low \\
3 & 10 & 70 & Medium \\
4 & 15 & 85 & Medium \\
5 & 20 & 110 & High \\
6 & 25 & 135 & High \\
\hline
\end{tabular}

Table 4. Flow Table Test Result.

\begin{tabular}{llllll}
\hline S/No & \% Contamination & Initial Concrete Base Diameter $(\mathbf{c m})$ & Average Concrete Diameter $(\mathbf{c m})$ & Flow Rate $(\mathbf{m} / \mathbf{s})$ & Flow Remark \\
\hline 1 & 0 & 25 & 29.0 & 16 & Very Low \\
2 & 2.5 & 25 & 32.5 & 30 & Low \\
3 & 10 & 25 & 35.5 & 42 & Low \\
4 & 15 & 25 & 37.0 & 48 & Low \\
5 & 20 & 25 & 40.0 & 60 & Medium \\
6 & 25 & 25 & 42.5 & 70 & Medium \\
\hline
\end{tabular}

Table 5. Average Compressive Strength.

\begin{tabular}{|c|c|c|}
\hline Description & Age (Days) & Strength $\left(\mathrm{N} / \mathrm{mm}^{2}\right)$ \\
\hline \multirow{4}{*}{ Control mix cured in portable water } & 7 & 30 \\
\hline & 14 & 31 \\
\hline & 21 & 32 \\
\hline & 28 & 35 \\
\hline \multirow{4}{*}{$\begin{array}{l}0 \% \text { Contaminated mix cured in bodo } \\
\text { crude oil water }\end{array}$} & 7 & 26 \\
\hline & 14 & 32 \\
\hline & 21 & 32 \\
\hline & 28 & 32 \\
\hline \multirow{4}{*}{$\begin{array}{l}2.5 \% \text { Crude oil mix cured in portable } \\
\text { water }\end{array}$} & 7 & 27 \\
\hline & 14 & 29 \\
\hline & 21 & 30 \\
\hline & 28 & 31 \\
\hline \multirow{4}{*}{$\begin{array}{l}5 \% \text { Crude oil mix cured in portable } \\
\text { water }\end{array}$} & 7 & 25 \\
\hline & 14 & 28 \\
\hline & 21 & 30 \\
\hline & 28 & 30 \\
\hline \multirow{4}{*}{$\begin{array}{l}10 \% \text { crude oil mix cured in portable } \\
\text { crude oil water }\end{array}$} & 7 & 23 \\
\hline & 14 & 30 \\
\hline & 21 & 30 \\
\hline & 28 & 30 \\
\hline \multirow{4}{*}{$\begin{array}{l}15 \% \text { Crude oil mix cured in portable } \\
\text { water }\end{array}$} & 7 & 27 \\
\hline & 14 & 30 \\
\hline & 21 & 26 \\
\hline & 28 & 29 \\
\hline \multirow{4}{*}{$\begin{array}{l}20 \% \text { Crude oil mix cured in portable } \\
\text { water }\end{array}$} & 7 & 24 \\
\hline & 14 & 25 \\
\hline & 21 & 25 \\
\hline & 28 & 26 \\
\hline \multirow{4}{*}{$\begin{array}{l}25 \% \text { Crude oil mix cured in portable } \\
\text { water }\end{array}$} & 7 & 19 \\
\hline & 14 & 20 \\
\hline & 21 & 22 \\
\hline & 28 & 20 \\
\hline
\end{tabular}

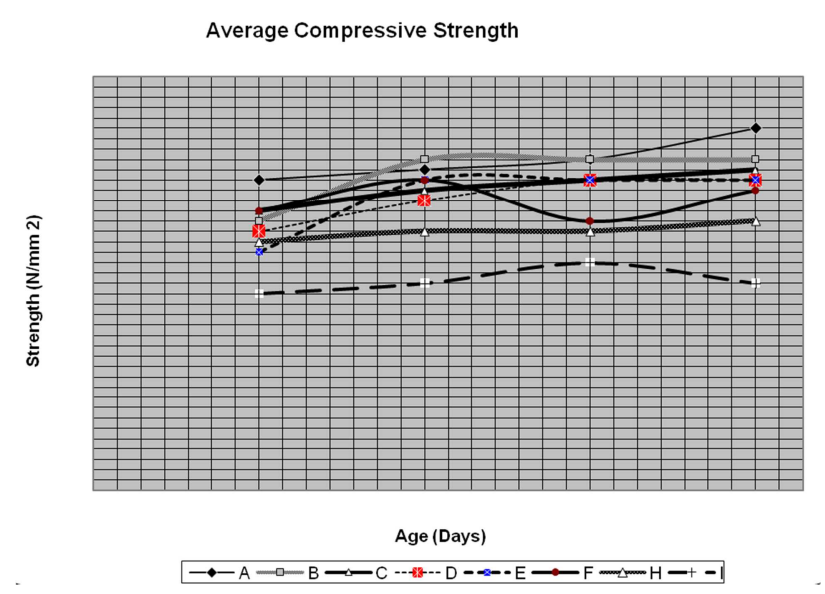

Figure 1. Graph of Average Compressive Strength against Age of Concrete.

Legend

A-Control mix cured in portable water

B- $0 \%$ Contaminated mix cured in bodo crude oil water

$\mathrm{C}-2.5 \%$ Crude oil mix cured in portable water

D-5\% Crude oil mix cured in portable water

E-10\% crude oil mix cured in portable crude oil water

F-15\% Crude oil mix cured in portable water

$\mathrm{H}-20 \%$ Crude oil mix cured in portable water

I-25\% Crude oil mix cured in portable water

\section{Discussion}

The results interpreted and presented in figure 1, tables 3, 4 and 5 respectively are explicit, but for the purpose of results discussion and interpretation clarity, it will be observed that the control mix for 28 days cured samples 
indicated the highest compressive strength of an average strength value of $35 \mathrm{~N} / \mathrm{mm}^{2}$ as compared to the $0 \%$ contaminated cube samples cured in Bode crude oil water with an average strength value of $31 \mathrm{~N} / \mathrm{mm}^{2}$ and the results kept on decreasing with increase in various percentage contamination of crude oil in the concrete constituent which finally brought the lowest average compressive strength to a value of $19 \mathrm{~N} / \mathrm{mm}^{2}$ which represent the 7 days $25 \%$ crude oil contamination mix. It may be interesting to note that the 28 days of the same $25 \%$ crude oil contaminated mix gave an average result value of $20 \mathrm{~N} / \mathrm{mm}^{2}$ which is $1 \mathrm{~N} / \mathrm{mm}^{2}$ difference from the 7 days of same $25 \%$ crude oil contaminated mix. This represents the processes which concrete structures under goes when it gain contact with oily substances, specifically in terms of crude oil which forms the basis of this research. In essence, the reduction in strength can be linked to the crude oil content in various percentages in the concrete constituent which has absorbed into the microstructure of the matrix of the concrete leading to delayed process in the gel of the cement as well as weakening the cohesiveness of the binder paste which is in conformity with the works of [15] and [3]. Also, other than the current observation of the reduced or slow compressive strength gain of the samples, the effect of crude oil on concrete structures worsens with time resulting to rotting of the structure. On the averages of the compressive strength results which fall from $32 \mathrm{~N} / \mathrm{mm}^{2}$ control sample to $30 \mathrm{~N} / \mathrm{mm}^{2}$ Sample cured in Bodo contaminated water down to $29 \mathrm{~N} / \mathrm{mm}^{2}$ for $2.5 \%, 28 \mathrm{~N} / \mathrm{mm}^{2}$ for $5 \%, 28 \mathrm{~N} / \mathrm{mm}^{2}$ for $10 \%, 28 \mathrm{~N} / \mathrm{mm}^{2}$ for $15 \%, 25 \mathrm{~N} / \mathrm{mm}^{2}$ for $20 \%$ and $20 \mathrm{~N} / \mathrm{mm}^{2}$ for $25 \%$ respectively for the crude oil contaminated samples. The flow table test is practically suitable for fresh concrete with high workability, in subjecting the sample to this test, it was clearly observed that the presence of crude oil in the concrete aided the workability as the percentage of flow rate of the control sample was very low indicating a value of $16 \%$ as compared to the highest level of percentage crude oil contaminated sample with percentage flow rate value of $70 \%$ as shown in table 4 . On the other hand, the slump values when compared with the highest contaminated sample of $25 \%$ have a difference of $120 \mathrm{~mm}$.

\section{Conclusion}

Having conducted the various practical and analysis in order to ascertain the strength of the concrete with respect to the effect of crude oil, the following conclusions were reached: That when concrete gain contact with liquid substances other than portable or fresh water, it may be considered injurious to the cement base material of such concrete, especially when it is OPC, as it has weak resistance to environmental and chemical reaction effect which causes slow strength development and ultimately low compressive strength when hardened as well as leading to concrete early rotting.

Finally, to ensure durability, rapid strength gain, avoidance of cracks, water tightness, abrasion resistance, volume stability, resistance to freeze and thaw and as well as resistance to deicing chemicals of OPC based structures, location of concrete constituents collection, mixing and curing water should be void of crude oil or other lubricants as such undiluted substances enhances high deterioration of concrete structures.

\section{References}

[1] Ajagbe, W.O., Omokehinde, S. O., Agbede, O.A. and Alade, G.A. (2011).Effect of Crude Oil Impacted Sand on Compressive Strength of Concrete. Construction Building Materials, Vol. 26, Issue 1 pp 9-12.

[2] Abdul-Ahad, R.B. and Muhammed, A.A. (2000).Compressive and Tensile Strength of Concrete Loaded and Soaked in Crude Oil, Engineering Journal of the University of Qatar, Vol. 13, pp 123-140.

[3] Onabolu, O. A. (1989). Effect of Hot Crude Oil on Concrete Offshore Storage Application. PhD Thesis, University of London. pp: 298.

[4] Matti, A. M. (1976). Some Properties and Permeability of Concrete in Direct Contact with Crude Oil. PhD Thesis, Sheffield University, UK pp: 230.

[5] Ukoli, M. K. (2001). Environmental Factors in Management of the Oil and Gas Industry in Nigeria. Posted in web. http://www.warmfloor.co.uk/pages/environmentalpdfbrochure. pdf.

[6] So O. and Nwankwo E.(2015).Effect Of Crude Oil Contamination On The Compressive Strength Of Concrete, Nigerian Journal of Technology, Vol. 34, No 2 (2015) pp 259-265 http://dx.doi.org/10.4314/njt.v34i2.7

[7] Akinwumi I. I., Diwa D and Obianigwe N (2014). Effects of Crude Oil Contamination on The Index Properties, Strength and Permeability of Lateritic Clay, International Journal of Applied Sciences and Engineering Research, Vol. 3, Issue 4, 2014, Received on July. 12, 2014; Accepted on August 6, 2014; Published on Aug. 29, 2014 http://DOI:10.6088/ijaser.030400007

[8] Wasiu A., Olusola S., Gabriel A. and Oluwole A. (2012). Effect of Crude Oil Impacted Sand on Compressive Strength of Concrete, Journal of Construction and Building Materials, 2012; 26(1):9-12.University of Ibadan, Ibadan, Nigeria http://DOI: 10.1016/j.conbuildmat.2011.06.028

[9] British Standard Institution (1983).Method for Determination Slump Test. (BS 1881: Part 102) London: British Standard Institution.

[10] British Standard Institution (1983).Method for Making Test Cubes from Fresh Concrete. (BS 1881: Part 1). London: British Standard Institution.

[11] British Standard Institution (1989). Method for Determination Particle Size Distribution. (BS 1881: Part 103).London: British Standard Institution.

[12] British Standard Institution (1983).Method for Determination Flow Table test. (BS 1881: Part 105) London: British Standard Institution.

[13] British Standard Institution (1983).Method for Determination Compressive Strength of Concrete Cubes from Fresh Concrete. (BS 1881: Part 116).London: British Standard Institution. 
[14] Ejeh, S. P. and Uche, O. A. (2009).Effect of Crude Oil Spill on Compressive Strength of Concrete Materials. J Appl Sci Res: $17,55-61$.
[15] Bangham, D. H. (1936).The Swelling and Shrinkage of Porous Materials and the Role of Surfaces in Determining Technical Strength. Symposium, Society of Chemical Industry; London. pp 269-333. 